\title{
Discussion on the Subconscious and its Visual Expression
}

\author{
Bo Zhang \\ School of Art and Design \\ Huanghe Science and Technology College \\ Zhengzhou, China \\ e-mail: 342640965@qq.com
}

\begin{abstract}
Surrealism is a literature and art school prevailing between two world wars. The inspiration and source of artistic creation mostly come from expression and symbolization of subconscious. Psychoanalytic theory of Freud is an important theoretical basis of surrealism. This paper aims at analyzing surrealism from the angle of vision and exploring how Dali expresses his dreamland through unique subconscious symbol.
\end{abstract}

Keywords-the subconscious; dreamland; psychoanalytic theory; visual arts; Dali

\section{INTRODUCTION}

In early 20th century, Freud founded psychoanalytic theory. The achievement and historical status of psychoanalysis lie in that it puts forward for the first time that aesthetics and art are built on human's subconscious, and makes subconscious become human's spiritual essence for the first time. [1] Subconscious is a special mental state and a person's internal mental process. Meanwhile, subconscious is also the best way to understand thoroughly people's inner thoughts. Surrealism is a literature and art school started from France. Its theory is influenced by psychanalysis of Freud, and advocates abandoning the reality image based on logical and ordered experience memory, and presenting the image world in human's deep psychology. Dali is a representative of surrealism painting. His works has a farreaching influence on visual arts..

\section{THE SUBCONSCIOUS AND ITS INVISIBILITY}

Sigmund Freud is the person who put forward the theory that human being have subconscious for the first time. This theory reveals the so-called unconsciousness and subconscious which are hidden in the heart, cannot be touched by people's consciousness, but have decisive significance for people's behavior. What are consciousness and subconscious after all? Some of human psychological activities can be perceived by us. As long as we focus attention, we can find ideas, images or emotions continually coming out of inner heart. Such mental activities can be realized by ourselves are called consciousness. However, some instinctive impulses, repressed desires or vitalities are unconsciously occurred in potential state. Since they do not conform to social morality and reasonable sense, they cannot be perceived by individual. The latent and unperceivable mental activities, such as thought, idea and desire, are called subconscious.

Freud divides human consciousness into three levels, namely, consciousness, preconsciousness and subconscious. Subconscious includes human's original impulse and various instincts; it is an irrational mental activity which is hidden deep inside, and cannot be realized or experienced by people under normal condition. There are instincts and desires which cannot be accepted by rationality and morality in the bottom of human's psychology. These potential strengths are the real "inner self" of individual life. Among which, the most intense is sexuality. The "inner self" in people's heart is the most fundamental motive power controlling human's behavior and thought. Although it is depressed by realistic norm, it often shows in the form of dream. Dream is a disguised satisfaction of subconscious, representing the most real aspect of humanity. [2] He analyzed the presentation of subconscious--dream in the Interpretation of Dream. He holds that dream is the most direct manifestation pattern of unconsciousness and subconscious, and an abreaction of instinct completely out of rational control. It reveals the undisclosed essence in the depth of human's soul.

Dreamland refers to various fantasy scenes in consciousness. Researchers including Freud hold that dream is based on life experience and living environment, and comes from reality. Reality is external, specified, real and visible. But dreamland is internal, unconstrained, illusory and invisible. Everyone dreams, but the dreamland is different, weird, and joyful, even twisted and blur. Subconscious is the best way to set the sheltered "inner self" free. One cannot directly see the other's dreamland. The indirect means generally makes use of language description, but it cannot completely disclose the dreamland.

\section{VisUALIZATION OF THE SUBCONSCIOUS AND ITS POSSIBILITY}

Freud holds that there are instincts and desires which cannot be accepted by rationality and morality in the bottom of human's psychology. The most intense desire of the id is sexuality. Although it is depressed by realistic norm, it constantly strives for self-satisfaction and frequently manifests in the form of dream. Dream becomes a form 
reflecting the reality of subconscious. Freud holds that the id of subconscious shall not be repressed. When repressed original impulse or desire which do not conform to social norm are expressed in constructive way conforming to social requirements. Such a psychological defense mechanism is sublimation, and forms such as painting, dancing and literature are embodiments of sublimation. All of them are the most common ways of expression for visualization of subconscious--visual arts activities. Among which, drawing is a good abreaction way. From the standpoint of psychoanalysis, materials in dream are the objective expression of subconscious. Creation of visual image is an embodiment of id surmounting social norm.

However, visual arts only depend on intuition, inspiration and creative thinking, and creative thinking is completed in subconscious and firstly realized in the threshold of consciousness. Many facts indicate that creative thinking is often demonstrated under relaxed mind in the way of inspiration and insight, even appears in sleep and dreamland. That is to say, the content of subconscious usually is the content that artist explores and expresses during artistic creation.

Affected by the subconscious theory of Freud, surrealism holds that there is a unconscious or subconscious world beyond the real world, advocates to abandon the reality image based on logical, ordered experience memory, presents the image world in human's deep psychology, tries to combine reality idea with instinct, and combine subconscious with dreaming experience, and further creates an absolute surmounting reality. Surrealism female Denmark painter Rita - Cohen - Larson uses "spiritual Odyssey" to compare the process of exploring subconscious and finding out true self. In her self-portrait, the field of subconscious is a deep ocean. Various marine plants and indescribable things under sea surface are the mysterious and complex subconscious kingdom. "Ego" Larson lonely wanders and explores in this sea kingdom, and tries to uncover the complicated mystery.

In paintings of Dali--the representative of surrealism, visual signs, such as ant, bread, soft clock, walking stick and drawer, can be frequently seen, which are closely related to his childhood and the reflection of his false or true childhood memory. Since he took over the injured bat from his elder male cousin in childhood, ant coming into Dali's memory is doom to be the will of Heaven. Dali devoted all his love to this injured small bat. But one day, nightmare came. Somehow his favorite small bat was surrounded by a crowd of crazy ants; the bat was beaten black and blue, trembling with pain and at the last gasp. He jumped up, took up bat crawling with ants, crunched the head of bat like crazy and threw it into water. Therefrom, ant had accompanied with Dali. Dali exactly uses these subconscious symbols symbolizing his childhood memory to interpret his potential creative complex. His works Dream describes a woman's mouth crawling with ants in dark. The whole picture gives people a feeling of fear and incomparable repression through the image of ant. Busy ants usually symbolize nervous, anxiety and aging, and imply the fear, inability, anxiety and sexual anxiety in subconscious of Dali.
Bread with solid appearance and soft interior is the symbolization of sexuality. Soft clock expresses Dali's anxiety and fear for time. In Dali's eyes, walking stick is the symbolization of "death" and "renascence"; In Dali's works, drawer mainly appears in female body, however, in the interpretation of Freud, drawer is the hidden lust of female; this also expresses Dali's fantasy for lust.

Artistic creation of surrealism just likes a dream. It is the expression and symbolization of subconscious. Artistic creation of surrealism wishes to present the world of subconscious through artistic work overturning life, use fantastic scene to replace realistic daily life, and create artistic conception transcending reality. Fantasy image of surrealism cannot be related to the conscious and rational attitude to world. The emphasis is not a certain type of artistic form, but to pursue the essence of dream, and liberation of spirit. Regarding this as the source, the surrealism artists emphasize the omnipotence of dream, artistic creation without rational restriction and free mobility of consciousness, and record the process of spontaneous activity or dream activity of consciousness. It is an aesthetic grasping method recording dream, links the imaged or fantastic product of human with reality through implicit figurativeness, and makes the visualization of subconscious possible.

\section{VISUAL EXPRESSION OF THE SUBCONSCIOUS AND ITS PROBLEMS}

Surrealism artists have the most prominent contribution to the study and visualization of subconscious. The dreamland expressed by surrealism school of painting not only emphasizes the importance of dreamland, but also boldly combines the logically unrelated images in indication manner, to create specific weird taste of dreamland. Upon creation, surrealism painter is good at separating a certain parts from objects with different natures, depriving specific functionality, arranging or combining these logically unrelated parts with implied meaning, and triggering subtle and subconscious association. For example, Favorable Model by Margaret boldly uses fancy creative imagination to decompose various representations of feet from human body, decompose the symbolic representation of shoe from shoes, combine illogical parts of the two, and create a reality in dreamland with more artistic appeal. Therefore, surrealism painters uses the subconscious field, dream illusion and instinct put forward by Freud as the source of creation, that is, art uses "illogicality" to adjust reality. Such a "unconsciousness", "non-rationality" and "illogicality" is a complicated and confusing realm or "sublimated" from dream. In their mind, the objective of art is to create a "superior reality".

In Behind the Mirror--a painting created by Larson, the thick mirror in the painting stands upright and makes the world behind the mirror a secret. The subconscious world can be entered, and the depressive "ego" can be found, only after the mirror is broken. Larson sees the subconscious world behind the mirror, however, the "ego" who is exploring and searching in front of mirror becomes lost, lonely and out of all recognition. Larson tries to pass through 
the illusory mirror and find the real subject behind the mirror. However, when one mirror is broken, the other mirror is erected again. He cannot find the real ego.

Many ideas and theories utilized by Dali in artistic creation are sourced from psychoanalytic theory. He always uses symbol mark and simplified image in works, and uses a language similar to abstract to express spontaneous induction of soul. He holds that artist shall accurately record the image of subconscious. Therefore, he adopts "concretization" to accurately reflect the phantom generated in abnormal logical thinking, combine completely irrelevant things together, make the scene full of dramatics and bring visual and spiritual shock to people.

For example, his works--Soft Construction with Boiled Beans projects the strongest disgust of humanity to the desperation of civil war through the imagination of sex and violence. The cruelty and non-rationality of war can be expressed by many ways, however, Dali completely and simply expresses the "sense of fear". He induces "fear" in the form of sexual violence through one pulled breast and an opposite ankle, and further induces fear with a ferocious and wailing head and several strange hands. Although there is nothing related to war on the picture, people have consistent feeling in psychology.

Dali uses the so-called "critical state of paranoia" to induce his own illusion world and produce image from subconscious. His explanation for surrealism is: The surrealism article shall be absolutely useless, and shall be absolutely ridiculous from the viewpoint of practicability; it shall maximally use palpability to reflect the spirit fantasy of crazy personality; the appearance and circulation of these articles launch a competition against useful and practical articles; the competition is so fierce that it makes people believe that they've witnessed a fight of angry cocks; normal articles are often plucked out of feathers and driven away in fight. [3] Dali indeed thoroughly implements this theory to his artistic works and life. He uses unique subconscious symbol to interpret his own dreamland. He abandons the noumenon of each thing in works and endows them a special meaning.

\section{CONCLUSION}

For surrealistic artists, subconscious is the only source of artistic creation, and the expression of subconscious content also becomes the fundamental objective of artistic creation. The creation of artist turns from conscious level to subconscious level, starts the artistic expression dominated by human's instinctive impulse, content of dreamland and view of dreamland. The content of subconscious has full visual expression, and the "id" is further explored in a deeper level.

\section{REFERENCES}

[1] Niu Hongbao. Western Modern Aesthetics [M]. Shanghai People's Publishing House, 2002, p221.

[2] (Austria) Freud, translated by Zhou Yanhong. The Interpretation of Dreams [M]. Shanghai Joint Publishing Co., 2008
[3] Salvador - Dali, translated by Chen Xunming. Dali Autobiography [M]. Gold Wall Press. 2012

[4] (Austria) Freud, translated by Yang Shaogang, et al. Psychical Philosophy by Freud [M]. Jiuzhou Press, 2003

[5] (Spain) Salvador Dali, translated by Chen Xunming, et al. Diary of a Genius [M]. Hunan Fine Arts Publishing House, 1997

[6] Wang Ye. Visual Image and Subconscious Analysis__-Influence of Psychoanalysis on Surrealism Painting [D]. Central China Normal University, 2009

[7] Chen Xiao. From Dream to Subconscious- Discussion on Concept of Subconscious by Freud through Dream Analysis [J]. Arts and Humanities, 2009(7)

[8] (America) Thomos Crow, translated by Yi Ying. Modernism and Mass Culture in the Visual Arts [M]. Hebei Fine Arts Publishing House, 2004

[9] [8] Zhai Mo, Wang Duanyan. Surrealism [M]. People's Fine Arts Publishing House, 2000

[10] Jin Xiaodan. Visual reflection of subconscious theory of Freud-Analyzing subconscious symbol in Dali's works [J]. The Border Economy and Culture, 2008(10). 